\title{
BMJ Open Cardiometabolic risk factors and mental health status among truck drivers: a systematic review
}

\author{
Amber J Guest (D) , ${ }^{1}$ Yu-Ling Chen (D) , ${ }^{1}$ Natalie Pearson (D) , ${ }^{1}$ James A King (i) ,1,2 \\ Nicola J Paine (D) , ${ }^{1}$ Stacy A Clemes (D) ${ }^{1,2}$
}

To cite: Guest AJ, Chen YL, Pearson N, et al.

Cardiometabolic risk factors and mental health status among truck drivers: a systematic review. BMJ Open 2020;10:e038993. doi:10.1136/ bmjopen-2020-038993

- Prepublication history and supplemental material for this paper are available online. To view these files, please visit the journal online (http://dx.doi. org/10.1136/bmjopen-2020038993).

Received 31 March 2020

Revised 30 July 2020

Accepted 11 August 2020

Check for updates

(C) Author(s) (or their employer(s)) 2020. Re-use permitted under CC BY-NC. No commercial re-use. See rights and permissions. Published by BMJ.

${ }^{1}$ School of Sport Exercise and Health Sciences, Loughborough University, Loughborough, UK ${ }^{2}$ National Institute for Health Research (NIHR) Leicester Biomedical Research Centre, University Hospitals of Leicester NHS Trust and the University of Leicester, Leicester, UK

Correspondence to

Amber J Guest;

a.guest@|boro.ac.uk

\section{ABSTRACT}

Objective This study aimed to systematically review and summarise the literature on cardiometabolic risk factors, lifestyle health behaviours and mental health status of truck drivers globally to ascertain the scale of these health concerns.

Design Systematic review reported using the Preferred Reporting Items for Systematic Reviews and MetaAnalyses guidelines.

Data sources PubMed, Scopus, PsycINF0 and Web of Science were searched in January 2019 and updated in January 2020, from the date of inception to 16 January 2020.

Eligibility criteria for selecting studies Papers were included if they (1) reported independent data on truck drivers, (2) included quantitative data on outcomes related to cardiometabolic markers of health, mental health and/or health behaviours, (3) were written in English and (4) were published in a peer-reviewed journal. Grey literature was ineligible for this review.

Data extraction and synthesis One reviewer independently extracted data and assessed methodological quality using a checklist based on the National Heart, Lung and Blood Institute Quality Assessment tool. 20\% were independently assessed for eligibility and quality by a second reviewer. Due to heterogeneity of the outcomes, results were narratively presented.

Results 3601 titles and abstracts were screened. Seventy-three studies met the inclusion criteria. Truck driving is associated with enforced sedentarism, long and irregular working hours, lack of healthy foods, social isolation and chronic time pressures. Strong evidence was observed for truck drivers to generally exhibit poor cardiometabolic risk profiles including overweight and obesity, hypertension, hypercholesterolaemia, high blood glucose, poor mental health and cigarette smoking. Conclusions Improving truck driver health is vital for the longevity of the trucking industry, and for the safety of all road users. The workplace plays a vital role in truck driver health; policies, regulations and procedures are required to address this health crisis.

PROSPERO registration number CRD42019124499.

\section{INTRODUCTION}

Truck driving encompasses an abundance of integral, interlinking health risk factors that create barriers to the adoption of healthy

\section{Strengths and limitations of this study}

- This review encompasses a comprehensive range of cardiometabolic markers of health and lifestyle factors that provides a rich description of the overarching health of truck drivers globally.

- This is the first systematic review to address the gap in the evidence base by examining the cardiometabolic health of truck drivers globally, following the Preferred Reporting Items for Systematic Reviews and Meta-Analyses guidelines.

- Meta-analysis was not possible due to heterogeneity in methods and descriptive presentation of results.

- This study assessed the risk of bias of each included paper including the informativeness and methodological quality.

- Findings could be impacted by a 'healthy worker effect', in that truck drivers in most countries must undergo and pass a medical assessment to maintain their licence, drivers who are at-risk may either choose not to enrol in studies or fail the medical examination and would therefore be excluded from the study samples, which could potentially bias the overall health profile of participants included within the reviewed studies.

lifestyle behaviours. These include long hours of enforced sedentarism, reducing opportunities for physical activity, limited availability of healthy food, irregular shift patterns and sleep deprivation. ${ }^{1}$ The isolated nature of the work results in a lack of peer social modelling and poor mental health. ${ }^{2}$ This is exacerbated by intense job demands and low levels of perceived job control, resulting in chronic time pressures compounded by tight delivery schedules and traffic conditions. ${ }^{3}$ Truck driving is a male-dominated industry comprising an ageing workforce. ${ }^{4}$ These factors are likely associated with the high prevalence of obesity, chronic diseases, mental ill health and reduced life expectancies seen in truck drivers in comparison to other occupational groups. ${ }^{5-8}$ The health and well-being of professional truck drivers is of public concern 
given their health impacts the safety of all road users. ${ }^{6}$ For example, truck drivers with obesity, cardiovascular disease, depression, anxiety or with $\geq 3$ comorbidities have a significantly increased risk of preventable crashes. ${ }^{9-13}$

There is a developing body of evidence relating to the physical and mental health of truck drivers which consist of small-scale independent studies. When efficiently aggregated together, these studies will establish whether the findings are consistent and hence provide greater strength with the ability to establish a better understanding of the international prevalence. This prompts the need for a systematic review and appraisal of data to facilitate health promotion interventions for this underserved occupational group. The objective of this paper was to systematically review the literature regarding the cardiometabolic and mental health profile of truck drivers globally.

\section{METHODS}

The review protocol was reported using the Preferred Reporting Items for Systematic Reviews and Meta-Analyses (PRISMA, see online supplemental material 1 and 2). ${ }^{14}$

\section{Search strategy}

A literature search for relevant papers was conducted in four electronic bibliographic databases: PubMed, Scopus, PsycINFO and Web of Science. Several synonyms of 'truck driver' were used such as 'HGV' and 'lorry driver', a truck driver in this paper is defined as somebody who earns a living transporting goods over land by operating a heavy goods vehicle, this means that the criteria would accept lorry drivers but reject bus, coach, van, taxi and train drivers. These were combined with a comprehensive list of forty key terms for risk factors, related health outcomes and lifestyle factors/behaviours to locate potentially relevant studies. Keywords were created with guidance from a research librarian to ensure a thorough scope was reached. An example of the search strategy used for PubMed is provided in online supplemental material 3. In addition, manual searches of reference lists of primary studies, reviews and identified articles were conducted. The search strategy was carried out in January 2019 and updated in January 2020.

\section{Patient and public involvement}

No patient involved.

\section{Inclusion criteria}

To be included in the review, the studies were required to (1) report independent data on truck drivers, (eg, if data were combined with bus drivers then they were excluded), (2) include quantitative data on outcomes related to cardiometabolic markers of health, mental health and/ or health behaviours, (3) be written in English and (4) be published in a peer-reviewed journal from the date of inception up to the 16 January 2020. All study designs were considered for inclusion.

\section{Identification of relevant studies}

The titles and abstracts of identified articles were simultaneously screened for eligibility by one reviewer (AG), $20 \%$ of which were randomly selected and verified by a second reviewer to ensure consistency (Y-LC), which resulted in a $96 \%$ agreement rate. If abstracts were not available or provided insufficient information, the entire article was retrieved and screened against the inclusion criteria. Any discrepancies in identification of relevant studies were discussed. If a decision could not be reached then a third reviewer was consulted (NPe).

\section{Data extraction}

Data were extracted from all included papers on standardised Excel spreadsheets by one reviewer (AG). Extracted data included: study design, country, sample size, sociodemographic information, measurement methods, main findings, funding source, markers of health (anthropometric measurements, blood pressure, blood profile, mental health) and lifestyle health behaviours (diet, physical activity, addictive behaviours).

\section{Methodological quality assessment}

Included studies were evaluated on their methodological quality using a checklist based on the National Heart, Lung and Blood Institute Quality Assessment tool for cross-sectional and cohort studies, ${ }^{15}$ though questions were tailored for this review. The questions referred to informativeness (two items) and study methodology (four items). It was scored as positive $(+)$, negative $(-)$ or not reported/applicable (?). The primary author (AG) scored the quality of each article, the second author (Y-LC) independently scored $20 \%$. The results of the scoring were compared, and differences were discussed and rectified with the assistance of a third author (NPe). Papers were deemed good if they met $\geq 5$ criteria, fair if they met 4 and poor if they met $\leq 3$ criteria.

\section{RESULTS}

\section{Search and selection}

The literature search yielded 3601 potentially relevant papers, of which 95 were included, representing 73 studies (figure 1). Online supplemental material 4 shows the studies which consist of multiple papers. Sample sizes ranged from 12 to 95567 . Study designs included crosssectional (53 studies, 68 papers), repeated cross-sectional (3 studies, 5 papers), case-control (5 studies/papers), retrospective cohort (4 studies/papers), prospective cohort (6 studies/papers) and interventions (5 studies, 7 papers) table 1 . Due to heterogeneity between study methodologies, a qualitative synthesis of the data was deemed most appropriate to draw conclusions about the cardiometabolic and mental health of truck drivers. ${ }^{16}$ See online supplemental material 5 for the full summary of included papers.

\section{Quality assessment}

A summary of the quality assessment of the included papers is shown in table 2. Individual paper quality 
24.15.
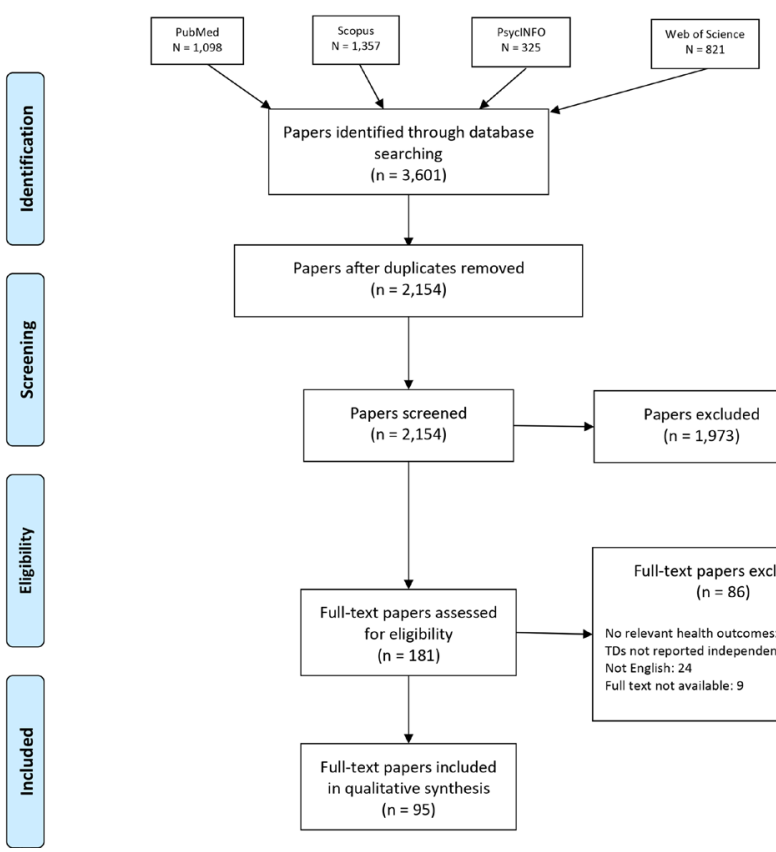

:

$$
(n=2,154)
$$
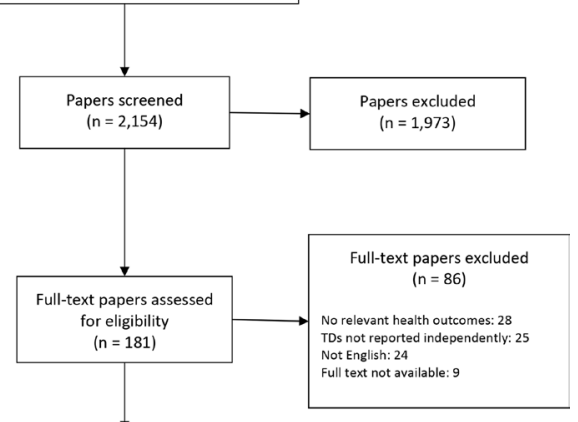

Full-text papers included $(n=95)$

Figure 1 PRISMA flow diagram of literature search and selection of studies in review. PRISMA, Preferred Reporting Items for Systematic Reviews and Meta-Analyses.

assessment has been provided in online supplemental material 6.

\section{Demographics}

Sixty-five studies included information on sex distribution $^{235} 911-1317-92$ of which, only $15 \%$ included $<90 \%$ males. ${ }^{11} 23263032364155576469$ Twenty-eight studies were conducted in North America, 12 in South America, 14 in Asia, 8 in Europe, 8 in Australia and 3 in Africa (table 1). Of the studies which reported average age of participants, the means ranged from $22.8^{66}$ to 56.3 years. ${ }^{91}$ Seventy-five per cent of studies reported mean ages over 40 years. $^{2} 511-13171822252628303133$ 35-39 41-44 47-57 59-61 6465 69-72 74757879 81-83 85 87-89 91-98 Twenty-four studies reported sample ethnicity, 21125263133 36-41 44 47495055576061636466 6773758489949798 with all but three including a majority of white participants. ${ }^{33} 6673$ Thirty-five studies described participants' education level, ${ }^{2} 131920252733 \quad 34364041$ 43-45 47-50575863-6971737577838689-9194969799 the percentage of those not completing high/secondary school ranged from $11.5 \%{ }^{69}$ to $96.7 \%,{ }^{27}$ though the overall trend was towards most participants having a low level of education, with the majority not completing secondary/high school education. Thirty-six studies reported classifications of truck drivers. Twenty-seven of these were long haul (ie, typically drives >250 miles per drop), 922252728303334 36-40 49-515355 60-65 68707375838589 93-9597100

typically drives $<150$ miles per drop ${ }^{4854}$ and six reported a combination of both long and short haul. ${ }^{17} 32596972101$ Two studies compared day shift and irregular shift truck drivers. ${ }^{19-21} 32$
Markers of health

Anthropometrics

Fifty-three studies reported body mass index (BMI) (table 1), $63.8 \%$ objectively measured height and weight, while $36.2 \%$ relied on self-reported data. Mean BMI ranged from $22.0^{27}$ to $39.7 \mathrm{~kg} / \mathrm{m}^{2}{ }^{28}$ Based on the WHO guidance for BMI thresholds for White European and Asian populations, ${ }^{102}$ only two studies reported an average healthy $\mathrm{BMI}^{27}{ }^{203}$ within their samples. Twentyseven studies reported a sample mean BMI within the overweight category; 9 19-24 29324043 45-48 52-54 58 71-74 80-82 85-89 96979923 studies were within the obese category. 2511121718 2526283031 37-39414244 49-51 55-5759697078798384949598100 One study reported obesity was twice as prevalent in a sample of US truck drivers than the US adult population. ${ }^{89}$

Sixteen studies included waist circumferences, ${ }^{11}$ 17-21 26-28 303738 40-42 476069738384879497 with 12 of these reporting average waist circumferences which indicate increased risk of developing adverse health conditions $(>102 \mathrm{~cm}$ Europids/>90 cm South Asians). 111718262830373841424760 698384879497104

\section{Blood pressure}

Nineteen studies included blood pressure measurements, ${ }^{511} 182123262837-39414247535460697379808283939798$ with average blood pressures ranging from $116 / 80^{23}$ to $142 / 87$ mmHg. ${ }^{18}$ Twenty-nine studies included prevalence of selfreported or objectively measured hypertension,, 3511121725 273334 39-43 $46495361-646970727578-808286-89$ 96-98 103 with thresholds ranging from $>140 />90$ to $>165 />95 \mathrm{mmHg}$, though many studies did not report the hypertension thresholds applied. Hypertension prevalence ranged from $3 \%{ }^{34}$ to $63 \%{ }^{17}$ Two studies found truck drivers with obesity had a higher prevalence of hypertension. ${ }^{468} 88$ Seventy-seven per cent of studies ${ }^{511} 17192739-42495362636975798286-889798$ ${ }^{103}$ indicated that the prevalence of hypertension in truck drivers was higher than the global prevalence $(26.4 \%) .{ }^{105}$

\section{Blood profile}

\section{Total cholesterol}

Twelve studies objectively measured total cholesterol levels. ${ }^{11} 1921262837-4247495461697388$ Most measurements were in $\mathrm{mg} / \mathrm{dL}$, mean readings ranged from $168.2 \mathrm{mg} /$ $\mathrm{dL}^{37}$ to $202.8 \mathrm{mg} / \mathrm{dL},{ }^{54}$ though the latter reading was not fasted. Six studies measured the prevalence of high total cholesterol levels. $^{19} 38-40496988$ Thresholds varied from $>190^{19}$ to $>240 \mathrm{mg} / \mathrm{dL}^{88}$ though the remainder ${ }^{38-40} 69106$ reported high total cholesterol based on the Adult Treatment Panel (ATP) III classification of $>200 \mathrm{mg} / \mathrm{dL} .{ }^{107}$ Of those using the $>200 \mathrm{mg} / \mathrm{dL}$ threshold, studies reported prevalence of borderline-high total cholesterol as $11.4 \%,{ }^{3839} 33.0 \%,{ }^{40} 38.8 \%{ }^{69}$ and $45.8 \%{ }^{106}$

\section{High-Density Lipoprotein (HDL)}

Eleven studies reported HDL, ${ }^{11} 1921262837-4247546061697383$ most measurements were in $\mathrm{mg} / \mathrm{dL}$, mean readings ranged from $29.0 \mathrm{mg} / \mathrm{dL}^{28}$ to $52.5 \mathrm{mg} / \mathrm{dL} \cdot{ }^{54}$ Forty three per cent of studies ( $\mathrm{n}=7$ studies) reported mean HDL level as low 


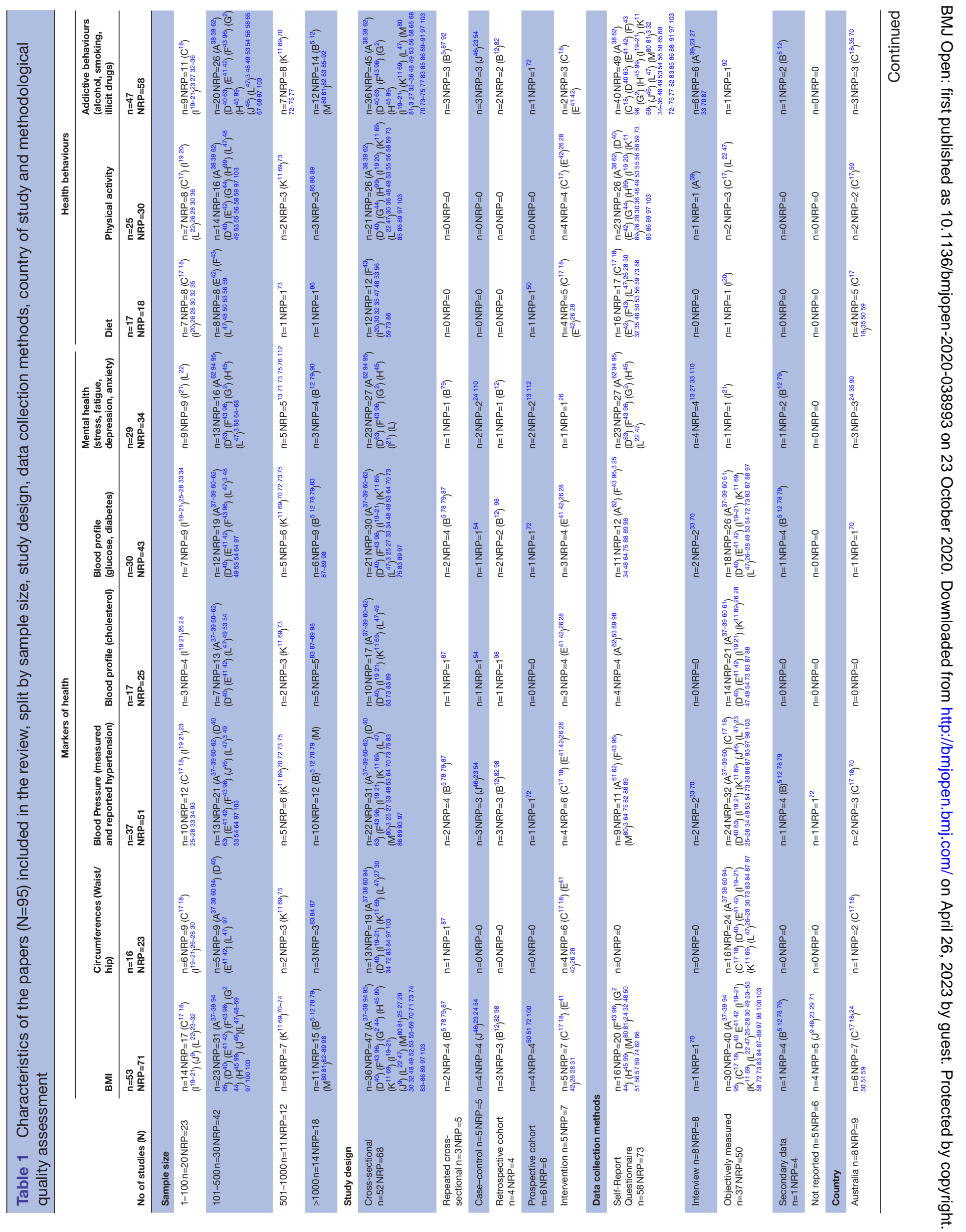




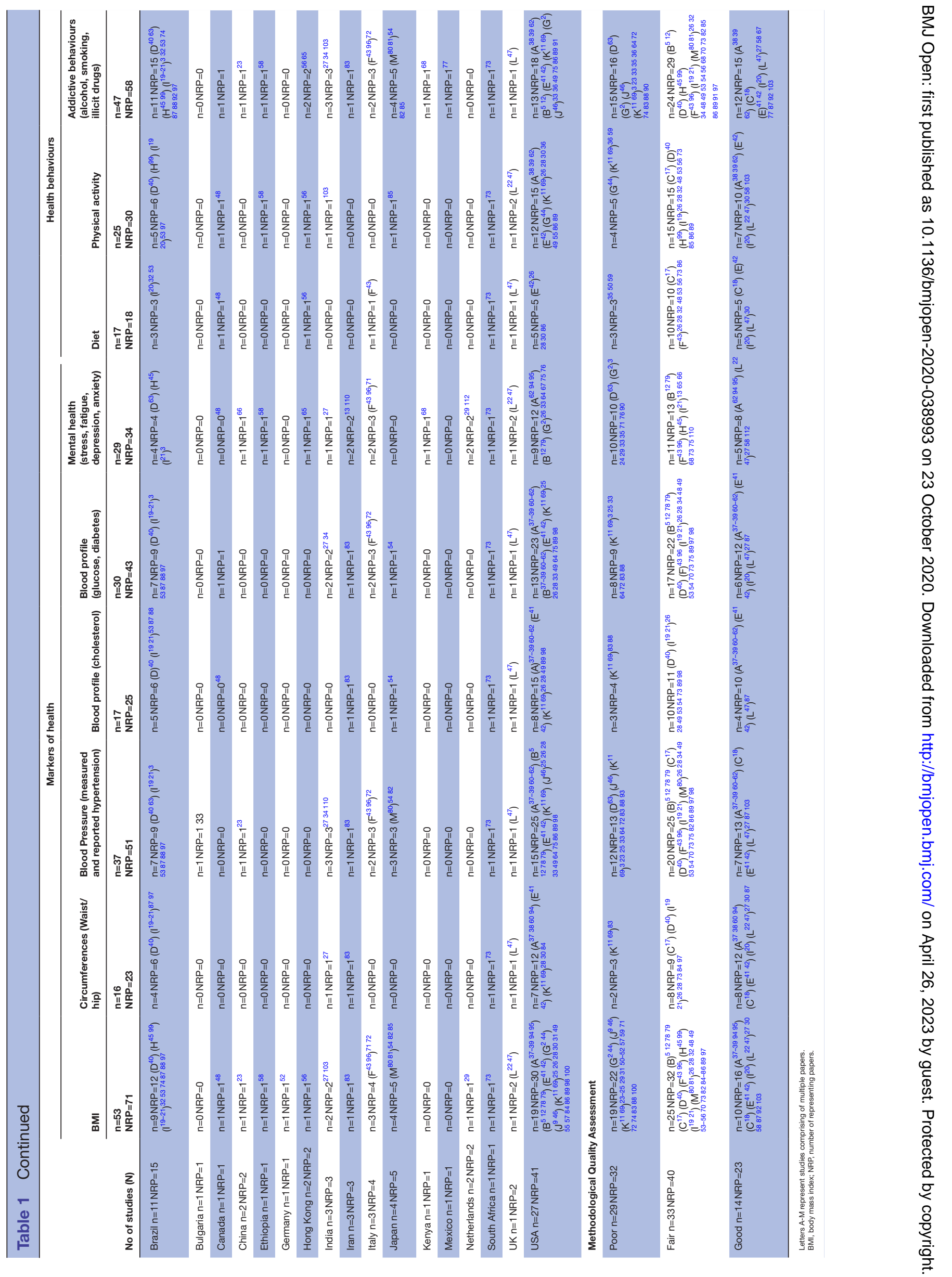


Table 2 Criteria list for assessment of methodological quality of papers

\begin{tabular}{|c|c|c|}
\hline Questions & Criteria measured & $\begin{array}{l}\% \text { Papers meeting } \\
\text { criteria }(n=95)\end{array}$ \\
\hline Q1: Was the research question or objective in this paper clearly stated? & Informativeness & 95 \\
\hline Q2: Was the study population clearly specified and defined? & Informativeness & 93 \\
\hline Q3: Was the participation rate of eligible persons at least $50 \%$ ? & Methodology & 32 \\
\hline $\begin{array}{l}\text { Q4: Were all the subjects selected or recruited from the same or similar populations } \\
\text { (including the same time period)? Were inclusion and exclusion criteria for being in the } \\
\text { study prespecified and applied uniformly to all participants? }\end{array}$ & Methodology & 69 \\
\hline $\begin{array}{l}\text { Q6: Were the markers of health/health behaviours/outcomes clearly defined, valid, } \\
\text { reliable and implemented consistently across all study participants? }\end{array}$ & Methodology & 78 \\
\hline \multicolumn{3}{|l|}{ Quality of papers (no of Questions meeting criteria) } \\
\hline
\end{tabular}

(<40 mg/dL), ${ }^{112837-39606169}$ based on the ATP III Classification of HDL cholesterol. ${ }^{107}$

\section{Low-Density Lipoprotein (LDL)}

Ten studies measured LDL levels, ${ }^{19} 2126283740-42476169$ 7383 most measurements were in $\mathrm{mg} / \mathrm{dL}$, mean readings ranged from $103.5 \mathrm{mg} / \mathrm{dL}^{28}$ to $150.4 \mathrm{mg} / \mathrm{dL}^{83}$ According to ATP III, all mean LDL values reported in $\mathrm{mg} / \mathrm{dL}$ were above optimal. Cavagioni et al found $25.2 \%$ of truck drivers had an LDL of $>130 \mathrm{mg} / \mathrm{dL},{ }^{40}$ which is borderline-high based on the ATP III classification of LDL cholesterol. ${ }^{107}$ This is supported by Lemke et al who found that $52.8 \%$ of truck drivers had an LDL level of $>115 \mathrm{mg} / \mathrm{dL}^{61}$

\section{Triglycerides}

Ninestudiesreported triglyceridelevels, ${ }^{1921263740-424760617383}$ mean readings ranged from $158.5 \mathrm{mg} / \mathrm{dL}^{40}$ to $203.1 \mathrm{mg} /$ $\mathrm{dL}^{21}$ All reported mean triglyceride levels were $>150$ $\mathrm{mg} / \mathrm{dL}$, which based on the ATP III classification of triglycerides is borderline-high. ${ }^{107}$

\section{Glycaemic control}

Seventeen studies measured fasting blood glucose levels, ${ }^{11} 1921$ 26-28 37-42 47 495354606973 83878897 most were reported in $\mathrm{mg} / \mathrm{dL}$, mean readings ranged from $86.3 \mathrm{mg} / \mathrm{dL}^{37}$ to $125.0 \mathrm{mg} / \mathrm{dL}^{53}$ Thirty three per cent of reported mean glucose levels were $>110 \mathrm{mg} /$ $\mathrm{dL},{ }^{11} 285369$ which based on the ATP III classification of fasting glucose, is a risk factor for the metabolic syndrome. ${ }^{107}$ Three studies measured Hemoglobin A1c (HbA1c), ${ }^{1149} 5469$ with means ranging from $5.0 \%{ }^{69}$ to $6.1 \%,{ }^{49}$ two studies of which, reported means within the pre-diabetic range of $\mathrm{HbA1c}$ level $(>5.7 \%)$ according to the American Diabetes Association. ${ }^{108}$ While three reported plasma glucose levels ${ }^{41} 4773$ which ranged from 5.2 to $5.7 \mathrm{mmol} / \mathrm{L}$.

\section{Diabetes}

Twenty-four studies reported prevalence of type 2 diabetes. ${ }^{3511} 12252733343741-434853616264697072737578798387-89$ 96-98 Self-reported previously diagnosed type 2 diabetes ${ }^{35}$ 122533344348616264697072757879899698 ranged from $1.5 \%{ }^{34}$ to $17 \%,{ }^{25}$ while prevalence in those with objectively measured abnormal glucose levels ${ }^{11} 192737425373838788$ ranged from $3.4 \%^{27}$ to $18.3 \% .^{37}$

\section{Metabolic syndrome}

Four studies reported metabolic syndrome prevalence. ${ }^{37-39} 41608387$ Apostolopoulos et al found a significantly higher proportion of US truck drivers had metabolic syndrome than a National Health and Nutrition Examination Survey comparative group ( $73.7 \%$ vs $33.8 \%$, respectively), ${ }^{37}$ similar findings have been reported elsewhere. ${ }^{41}$ Ebrahimi et al also found a high prevalence of the metabolic syndrome in Iranian truck drivers of $26.1 \%$ based on the ATP definition ${ }^{107}$ and $32.6 \%$ based on the International Diabetes Federation definition of metabolic syndrome. 83109

\section{Mental health \\ Depression}

Nineteen studies reported depression and depressive symptoms prevalence. ${ }^{2} 31322243335434762-687375769096110$ There were limited consistent measurements of depression; self-reported questionnaires were the measurement tool used in 17 studies, $^{2} 3132224354762-6873757690110$ one study conducted qualitative interviews, ${ }^{33}$ and one study reported depression medication use as 0.6\%. ${ }^{43} 96$ Selfreported symptoms of depression ranged from $6 \%{ }^{90}$ to $26.9 \%,{ }^{2} 40.8 \%$ of a sample of Kenyan truck drivers reported feeling depressed. ${ }^{68}$ In a large sample of US occupational groups, Fan et al found truck drivers had a twofold higher prevalence of depression than the average US worker. ${ }^{76}$ Alavi et al found that depression could 
increase the likelihood of a road traffic collision in truck drivers (OR 2.4). ${ }^{13}$

\section{Anxiety}

Eight studies reported anxiety prevalence. $^{2} 13222433434762679096$ Those that compared truck drivers anxiety levels to national averages, found truck drivers had significantly higher values of anxiety. ${ }^{2} 24767$ Anxiety was associated with a fourfold increase in likelihood of crashes. ${ }^{13}$ Though it appeared self-reported medication use for anxiety was low compared with that of the general population. ${ }^{4396111}$

\section{Stress}

Ten studies reported on psychological stress. $^{721} 2762677690949599110112$ Ulhoa et al found cortisol levels 30 minutes after wakening were higher in irregular shift workers compared with day-shift workers. ${ }^{21}$ Orris et al used a Symptom Checklist $90 \mathrm{R}$ questionnaire and found US truck drivers were in the 91st percentile for psychological distress compared with the US working population. ${ }^{67}$ Similar results were also seen in China. ${ }^{66}$ In a separate study, Ulhoa et al used a Self-Report Questionnaire and found that $6.1 \%$ of the sample had minor psychiatric disorders, with the most common reported stressors being traffic congestion, strict vehicle tracking control, and extended working hours. Thirty-three per cent reported high job demand and 54.9\% reported low job control, which were associated with minor psychiatric disorders. ${ }^{45}$ Croon et al conducted a 2-year prospective cohort study which found that job movement to any job outside of the trucking industry resulted in a larger strain reduction compared with job movement within the trucking industry. ${ }^{112}$

\section{Isolation}

Four studies reported on isolation. ${ }^{2} 3345110$ Ulhôa et al found $60.8 \%$ of truck driver reported low social support in the workplace. ${ }^{45}$ Hatami et al showed significantly reduced prevalence of depression in truck drivers who have a codriver than solo truck drivers. ${ }^{110}$ Shattell et al reported $27.9 \%$ of truck drivers mentioned being lonely ${ }^{2}$ and $27.1 \%$ mentioned they did not have good friendships, with $15.3 \%$ saying they had no friends. ${ }^{33}$

\section{Health behaviours}

Diet

Seventeen studies reported truck drivers' diet 171820262830 323542434748505356597386 ; of which nine studies measured daily fruit and vegetable intake. ${ }^{17182630424750565973}$ This ranged from 1.72 servings/day ${ }^{30}$ to 5 servings/day. ${ }^{47}$ It is suggested that at least five portions (>400 g) of varied fruits and vegetables should be consumed each day to prevent all-cause mortality, cancers and cardiovascular disease. ${ }^{113}$ Wong et al found that only $1.1 \%$ of truck drivers from Hong Kong ate $\geq 5$ portions of fruits/vegetables per day. ${ }^{56}$ Reis et al reported that $58.3 \%$ of Brazilian long haul truck drivers ate an 'unhealthy diet ${ }^{53}$ similar results were also found in Canada (48\%), ${ }^{48}$ though neither study reported how this was defined. Additionally, Olson et al found that $36.6 \%$ of calories in the diet came from fat, ${ }^{26}$ exceeding the higher threshold of $15-30 \%$ based on WHO guidelines. ${ }^{114}$ Korelitz et al reported $13.6 \%$ of truck drivers ate $>3$ snacks per day, while the majority of participants $(51 \%)$ ate two meals per day. ${ }^{86}$ Wong et al reported that $24.9 \%$ of truck drivers from Hong Kong ate at restaurants $>10$ times a week, this was significantly higher than their professional driver counterparts such as taxi and bus drivers. ${ }^{56}$ This is pertinent as the average calorie content in meals from restaurants regularly exceeds that of home cooked meals. ${ }^{115}$

\section{Physical activity}

Twenty-six studies observed physical activity levels in truck drivers, ${ }^{11} 1719202628303638-40424447495355565859697385868997$ 99103 however, only two studies objectively measured physical activity using an accelerometer (GENEActiv) ${ }^{17} 18$ and inclinometer (activPAL3). ${ }^{22} 47$ Though measurements of physical activity were heterogenous, overall the vast majority of truck drivers did not reach WHO physical activity guidelines. ${ }^{116}$ Sangaleti et al found $72.8 \%$ of Brazilian truck drivers were physically inactive, ${ }^{97}$ this is supported by Marqueze et al who found $66.7 \%$ of truck drivers completed $<10$ min of physical activity a week. ${ }^{19}$ Similar results were found in USA and Ethiopia, with $69.4 \%$ and $63.8 \%$ of truck drivers reporting no regular exercise, respectively. ${ }^{44} 58$ The highest self-reported regular exercise was $57.7 \%$ of truck drivers within a different US sample ${ }^{1169}$ and $42.9 \%$ of truck drivers in Hong Kong, ${ }^{56}$ however, Korelitz et al found only $8 \%$ of US truck drivers reported regular physical activity, while $49.6 \%$ reported never doing physical activity. ${ }^{86}$ Layne $e t$ al found minimal differences between male and female truck drivers levels of physical activity. ${ }^{36}$

\section{Sedentary behaviour}

Sevenstudiesreportedsedentarybehaviour. ${ }^{11172238-4047629799}$ The percentage of waking time spent sedentary in truck drivers varied from $39.4 \%^{38}{ }^{39}$ to $78.1 \% .^{53}$ One study objectively measured sitting time in a sample of truck drivers using inclinometers (activPAL3) and observed truck drivers spent 13 hours/day sitting on work-days, and 8 hours/day sitting on non-workdays. ${ }^{47}$ Shorter accelerometer-determined sedentary durations of 9.1 hours/workday were found in an Australian sample. ${ }^{17}$ A sample of truck drivers in the USA also self-reported sitting for an average of 4.3 hours/day outside of work. ${ }^{11}$

\section{Addictive behaviour \\ Smoking}

Thirty-eight studies reported on smoking status. ${ }^{3} 11$ 18-21 23 2734 36 38-42 46-49 535456636569707277808283 86-89 919697103 Prevalence of current smokers ranged from $10 \%^{73}$ to $72.9 \%,{ }^{83}$ however, categorising 'current smokers' varied between studies and was not defined in some. Jain et al found long haul truck drivers were more likely to smoke than delivery drivers, dock workers, mechanics or clerks. ${ }^{91}$ Mansur et al 
found that the smoking prevalence in truck drivers has decreased from 2006 to 2011 by $1.4 \%,{ }^{87}$ though Sieber $e t$ alshowed that compared with the US adult working population, US long haul truck drivers were more than twice as likely to smoke (51\% vs $19 \%) \cdot{ }^{89}$ Moreno et al found that although overall prevalence of smoking was high, those who were obese were less likely to smoke. ${ }^{88} 77 \%$ of studies that reported smoking status, reported higher smoking prevalence rates than the global average of $20 \% .{ }^{117}$

\section{Alcohol consumption}

Thirty-five studies measured alcohol consumption. ${ }^{2} 3511$ $182021232732-3540434753545658626365$ 68-70 727375 80-82 85-90 9799

Alcohol consumption was diversely measured. da SilvaJúnior et al reported $48.3 \%$ of a sample of Brazilian truck drivers admitted to drinking alcohol during working hours, and $88.6 \%$ were aware of similar behaviour in colleagues. ${ }^{3}$ Rosso et al also found $24.2 \%$ of a sample of Italian truck drivers reported drinking during working hours or breaks. ${ }^{43}$ Kartikeyan et al observed that over half of the Indian truck drivers assessed were classified as alcoholics (ie, consuming $>75 \mathrm{~g}$ alcohol/day), ${ }^{34}$ this is supported by Sharma et al, where $57.6 \%$ of their Indian truck driving sample were classified as alcoholics. ${ }^{27}$ Rice et al reported that $14.2 \%$ of Australian truck drivers admit to drinking excessively. ${ }^{35}$ Hilton et al found that using the Alcohol Use Disorders Identification Test questionnaire, 26.8\% of their sample of Australian truck drivers were considered alcohol dependent. ${ }^{90}$ Mansur found that alcohol consumption in Brazilian truck drivers has decreased from $36.6 \%$ in 2006 to $23 \%$ in 2011, however, illicit drug use has nearly doubled from $4.1 \%$ in 2006 to $8.1 \%$ in $2011 .^{87}$

\section{Illicit substances}

Seventeen studies measured illicit substance use. ${ }^{2} 31233$ $3540454963687072-75879297$ Overall self-reported drug use was low. Ulhôa et al reported that $0 \%$ of Brazilian participants asked used psychotropic drugs, ${ }^{45}$ which is similar to findings from a US study. ${ }^{12}$ However, Shattell $e t$ al found a relatively high prevalence of reported use of cannabis $(3.4 \%)$, opioids $(2.5 \%)$ and sedatives $(1.8 \%)$ in the past month in a sample of US truck drivers. ${ }^{2}$ Riva $e t$ al found a higher drug use in a sample of Italian truck drivers where $15.6 \%$ reported using recreational drugs, and of those, $12 \%$ reported they were addicted. ${ }^{72} 7.8 \%$ of a sample of Brazilian truck drivers tested positive for psychoactive substances. ${ }^{92}$ Shattell et al interviewed 60 specially selected long haul truck drivers based on their involvement in illegal/illicit behaviours, they found $88.1 \%$ admitted to drug use, and of those, $81.6 \%$ used crack cocaine. ${ }^{33}$ Selfreported stimulant use was high in several studies. ${ }^{306397}$

\section{DISCUSSION}

The aim of this review was to systematically summarise the literature regarding cardiometabolic risk factors, lifestyle health behaviours and mental health status of truck drivers globally. Findings suggest truck drivers are an at-risk occupational group, exhibiting unhealthy lifestyle behaviours, such as high levels of physical inactivity and sedentary behaviour, poor dietary choices, high consumption of alcohol and high smoking prevalence. This is reinforced by the reported markers of health such as high obesity levels, adverse blood profiles and mental ill health.

Another considerable risk factor for developing cardiometabolic health conditions is age, with truck drivers included in this review typically being middle aged. This is representative of that seen in the real-world setting, where truck drivers are classified as an ageing workforce. ${ }^{118}$ Nevertheless, one repeated cross-sectional study in the USA found that the average age of truck drivers has dropped between 2005 and 2012, ${ }^{79}$ which is an optimistic trajectory for the future of the road transportation and logistics industry.

It is apparent that truck driving is not conducive to health. Predictive factors for obesity were found to be time behind the wheel, ${ }^{96}$ travelling more than 40000 miles per year ${ }^{96}$ and working $>11$ hours $/$ day. ${ }^{95}$ Interestingly, truck drivers with obesity were significantly more likely to rate the exercise environment as bad, and therefore, had more perceived barriers to exercise. ${ }^{99} \mathrm{~A}$ repeated cross-sectional study of USA truck drivers found that BMI has increased significantly from 2005 to 2012. ${ }^{79}$ Similarly, the presence of dyslipidaemia had significantly increased from 2006 to $2011 .^{87}$ The increase in incidence of obesity and cardiometabolic biomarkers is alarming for the future of truck driving, especially considering drivers with obesity have significantly higher crash risks than healthy weight drivers. ${ }^{10} 44$ Obesity also has an economic impact to the employer, as truck drivers with overweight and obesity exhibit higher annual healthcare costs than healthy weight truck drivers. ${ }^{98}$ This is particularly pertinent for companies that cover employee health insurance costs.

\section{Implications for future research}

Future research is required to evaluate the health of truck drivers in lesser studied regions to gain a more global understanding of the health and implications of truck driving worldwide. Health and well-being programmes that focus on health education should be implemented and prioritised within the logistics industry. In truck drivers, improved education levels have been associated with increased physical activity, ${ }^{99}$ reduced $\mathrm{BMI}^{43}$ and improved mental health status. ${ }^{3}$ Where they exist, health and well-being programmes within this industry have been recognised as having the potential of providing beneficial impact on employee health, morale and employee-employer relations. ${ }^{119}$ This would also directly benefit employers with increased employee retention, reduced healthcare costs, improved safety and job desirability, combatting the global driver shortage. ${ }^{118}$

Despite their potential, limited health promotion programmes currently exist within the logistics industry and most have been minimally effective. ${ }^{6}$ Though primary prevention is vital, interventions should aim to reach a multitude of risk factors by applying multiple 
components, targeting health literacy and improving workplace opportunities to make healthy lifestyle choices, in order to gain maximum effectiveness. Research should then determine which components are most effective for improving driver health, ${ }^{26}$ and which facilitators and barriers may have affected participant adherence. ${ }^{120}$ All stakeholders including drivers, employers, unions, clinicians, truck stops, regulatory agencies and policy-makers should be engaged to achieve these ambitions.

\section{Strengths and limitations}

A key strength is the comprehensive review itself, encompassing a large range of cardiometabolic risk factors, health-related behaviours and mental health, thus providing a complete scope of the health status of truck drivers. Strengths also include the thorough search strategy; however, it is possible that some relevant papers were missed due to the English-only search criteria. A further strength is the stringent independent scoring of each paper's methodological quality. One reviewer screened all titles, abstracts, and full texts for inclusion followed by a methodological quality assessment of each included paper. Subsequently, 20\% were randomly selected for independent verification at each stage by a second reviewer, which is identified as a limitation of this paper based on the PRISMA guidelines.

Similarly, 33\% of included papers were scored 'poor' in the quality assessment, and $24 \%$ included small sample sizes $(n=<100)$ which may impact the confidence within the results.

Due to the heterogeneity of measuring and reporting findings from each study, a descriptive synthesis of results appeared most appropriate, though this may have led to inconsistent statistical findings between papers. As a recommendation for future research, authors are encouraged to report and use consistent thresholds for defining the prevalence of certain risk factors to enable a metaanalysis. By presenting all study characteristics and results in online supplemental file 4, transparency has been added. A limitation is the unequal geographical distribution of papers (table 1), ethnicity was predominantly White in all but two studies, ${ }^{3366}$ suggesting the review may not provide a complete representation of the global cardiometabolic and mental health status of truck drivers.

Truck driving is a very heterogeneous job, there are many varieties of truck drivers, predominantly long haul or short haul. Typically, short haul truck drivers are more physically active as they are often loading and unloading their trucks, the distances they travel are smaller and hence their sedentary time is often broken up. They also tend to return home after most shifts and drive less miles overall, which results in an overall healthier way of life. Only 36 included studies reported on the type of truck driver, which warrants consideration.

Another important factor is the law in many countries requires truck drivers to be of adequate health in order to legally operate commercial vehicles on public roads, and as a result, truck drivers are required to undergo regular medical examinations. Truck drivers may be disqualified for a multitude of health conditions and subsequently leave the industry. Consequently, a substantial healthy worker effect is created, as those who are unfit to work will not be included in studies. ${ }^{121}$ This may lead to the prevalence of diseases being low, while the prevalence of risk factors for chronic disease are substantial. ${ }^{48}$ This reflects the findings from this systematic review, where for example, only $41 \%$ of papers reported a mean higher prevalence of type 2 diabetes than the global average $\left(9.3 \%\right.$ in 2019). ${ }^{122}$

Notably, addictive behaviour such as alcohol and illicit drug consumptions are likely to be underreported due to fears that it may lead to disciplinary action. ${ }^{123}$ Participation bias may also impact these findings, for example, drivers at risk of certain health conditions may choose to not enrol in such studies. This is exacerbated by the certain levels of mistrust frequently seen among truck drivers, often resulting in their reluctance to release personal information, making them a hard-to-reach population. ${ }^{124}$

Similar reviews examining the health of truck drivers have found comparable findings. Abu Dabrh et al found that the average BMI of 32 combined studies of truck drivers was $30.5 \mathrm{~kg} / \mathrm{m}^{2}$ and the prevalence of hypertension was $23 \%(\mathrm{n}=1000) .{ }^{125}$ A systematic review which examined the health of truck drivers in North America also found the average BMI for all nine included studies was $>30 \mathrm{~kg} / \mathrm{m}^{2}$. ${ }^{126}$ This is further supported by Prince et al who compared cardiometabolic health variability between occupational groups, and found driving-based workers had a higher BMI and blood pressure than other occupational groups. ${ }^{127}$ Similarly, a literature review of truck drivers found hypertension in seven studies ranged from $24 \%$ to $47.9 \%$, the majority were above the global average. ${ }^{105} 128$

\section{CONCLUSION}

Based on the results of this review, there is strong evidence to indicate that truck drivers have a detrimental cardiometabolic and mental health profile in comparison to general populations. Obesity levels and other cardiometabolic risk factors in truck drivers are alarming considering it impacts the safety of all road users. Improving truck driver health is vital for the longevity of the trucking industry. It is imperative to understand that the systemic working conditions that truck drivers endure create a fundamental barrier to the adoption of a healthy lifestyle. These unique job demands include the long irregular hours of enforced sedentarism, which suppress the opportunity for physical activity, alongside the lack of healthy food choices at truck stops, which creates an obesogenic working environment. The workplace plays a vital role in truck driver health; policies, regulations and procedures are required to change in order to address this health crisis. 


\section{Twitter Stacy A Clemes @StacyClemes}

Contributors All authors contributed to the conception of the review. AG completed the literature search and quality assessments, Y-LC quality checked $20 \%$ of papers at titles, abstract, and full text for inclusion and methodological quality assessment. Any discrepancies were resolved by NP. NP, SC, NJP and JAK revised for critically important content. All authors approved the final version of the manuscript.

Funding The first author (AG) has received funding for their PhD Studentship from the Colt Foundation. The Colt Foundation had no role in study design; election, synthesis and interpretation of data; writing of the report; or the decision to submit the manuscript for publication. SC and JAK are in receipt of funding from the NIHR Public Health Research Programme (reference: NIHR PHR 15/190/42) for the evaluation of a multi-component health behaviour intervention in truck drivers. They are also supported by the NIHR Leicester Biomedical Research Centre - Lifestyle theme. The views expressed are those of the authors and not necessarily those of the NHS, the NIHR or the Department of Health and Social Care.

Competing interests None declared.

Patient consent for publication Not required.

Provenance and peer review Not commissioned; externally peer reviewed.

Data availability statement All data relevant to the study are included in the article or uploaded as online supplemental information. All data generated in this study are included in this published article and its additional files, no additional data are available.

Open access This is an open access article distributed in accordance with the Creative Commons Attribution Non Commercial (CC BY-NC 4.0) license, which permits others to distribute, remix, adapt, build upon this work non-commercially, and license their derivative works on different terms, provided the original work is properly cited, appropriate credit is given, any changes made indicated, and the use is non-commercial. See: http://creativecommons.org/licenses/by-nc/4.0/.

\section{ORCID iDs}

Amber J Guest http://orcid.org/0000-0002-3610-347X

Yu-Ling Chen http://orcid.org/0000-0002-6976-4055

Natalie Pearson http://orcid.org/0000-0003-2060-5966

James A King http://orcid.org/0000-0002-8174-9173

Nicola J Paine http://orcid.org/0000-0001-9988-9310

Stacy A Clemes http://orcid.org/0000-0001-5612-5898

\section{REFERENCES}

1 Caddick N, Varela-Mato V, Nimmo MA, et al. Understanding the health of lorry drivers in context: a critical discourse analysis. Health 2017;21:38-56.

2 Shattell M, Apostolopoulos Y, Collins C, et al. Trucking organization and mental health disorders of truck drivers. Issues Ment Health Nurs 2012;33:436-44.

3 da Silva-Júnior FP, de Pinho RSN, de Mello MT, et al. Risk factors for depression in truck drivers. Soc Psychiatry Psychiatr Epidemiol 2009;44:125-9.

4 Freight Transport Association. The Freight transport association logistics report, 2018. Available: https://fta.co.uk/CMSPages/ GetFile.aspx?guid=f34d2685-a763-4cd1-bda8-221020fcad3b\& lang=en-GB

5 Thiese MS, Hanowski RJ, Moffitt G, et al. A retrospective analysis of cardiometabolic health in a large cohort of truck drivers compared to the American working population. Am J Ind Med 2018;61:103-10.

6 MK N, Yousuf B, Bigelowa PL, et al. Effectiveness of health promotion programmes for truck drivers: a systematic review. Health Educ J 2015;74:270-86.

7 Apostolopoulos Y, Sönmez S, Shattell MM, et al. Worksite-induced morbidities among truck drivers in the United States. Aaohn J 2010;58:285-96.

8 Belzer S. Truck driver occupational safety and health: 2003 conference report and selective literature review, 2007. Available: https://www.researchgate.net/publication/318848708_Truck_Driver Occupational_Safety_and_Health_2003_Conference_Report_and_ Selective_Literature_Review [Accessed 20 Nov 2019].

9 Stoohs RA, Guilleminault C, Itoi A, et al. Traffic accidents in commercial long-haul truck drivers: the influence of sleepdisordered breathing and obesity. Sleep 1994;17:619-23.

10 Anderson JE, Govada M, Steffen TK, et al. Obesity is associated with the future risk of heavy truck crashes among newly recruited commercial drivers. Accid Anal Prev 2012;49:378-84.
11 Ronna BB, Thiese MS, Ott U, et al. The association between cardiovascular disease risk factors and motor vehicle crashes among professional truck drivers. J Occup Environ Med 2016;58:828-32.

12 Thiese MS, Hanowski RJ, Kales SN, et al. Multiple conditions increase preventable crash risks among truck drivers in a cohort study. J Occup Environ Med 2017;59:205-11.

13 Alavi SS, Mohammadi MR, Soori H, et al. The cognitive and psychological factors (personality, driving behavior, and mental illnesses) as predictors in traffic violations. Iran J Psychiatry 2017;12:78-86.

14 Liberati A, Altman DG, Tetzlaff J, et al. The PRISMA statement for reporting systematic reviews and meta-analyses of studies that evaluate healthcare interventions: explanation and elaboration. BMJ 2009;339:b2700.

15 National Institutes of Health. National heart, lung, and blood Institute quality assessment tool for cross-sectional and cohort studies, 2014. Available: https://www.nhlbi.nih.gov/health-topics/ study-quality-assessment-tools

16 Mueller M, D'Addario M, Egger M, et al. Methods to systematically review and meta-analyse observational studies: a systematic scoping review of recommendations. BMC Med Res Methodol 2018;18:44.

17 Gilson ND, Pavey TG, Vandelanotte C, et al. Chronic disease risks and use of a smartphone application during a physical activity and dietary intervention in Australian truck drivers. Aust N Z J Public Health 2016;40:91-3.

18 Gilson ND, Pavey TG, Wright OR, et al. The impact of an m-Health financial incentives program on the physical activity and diet of Australian truck drivers. BMC Public Health 2017;17:467.

19 Marqueze EC, Ulhôa MA, Moreno CRdeC. Effects of irregular-shift work and physical activity on cardiovascular risk factors in truck drivers. Rev Saude Publica 2013;47:497-505.

20 Marqueze EC, Ulhôa MA, Castro Moreno CR, et al. Leisure-time physical activity does not fully explain the higher body mass index in irregular-shift workers. Int Arch Occup Environ Health 2014;87:229-39.

21 Ulhôa MAJ, Marqueze EC, Kantermann T, et al. When does stress end? evidence of a prolonged stress reaction in shiftworking truck drivers. Chronobiol Int 2011;28:810-8.

22 Varela-Mato V, Clemes SA, King J, et al. Associations between musculoskeletal conditions risk, sedentary behavior, sleep, and markers of mental health: a cross-sectional observational study in heavy goods vehicle drivers. musculoskeletal conditions risk in HGV drivers. J Occup Environ Med 2019;61:437-43.

23 Baccarelli A, Barretta F, Dou C, et al. Effects of particulate air pollution on blood pressure in a highly exposed population in Beijing, China: a repeated-measure study. Environmental Health 2011;10:108.

24 Chalmers T, Lal S. Prevalence of affective states in Australian truck and train drivers. J Australas Coll ROAD Saf 2016;27:13-18.

25 Heaton K, McManus BJ, Mumbower R, et al. A pilot study of sleep, work practices, visual processing speed, and 5-year motor vehicle crash risk among truck drivers. Workplace Health Saf 2017;65:572-9.

26 Olson R, Anger WK, Elliot DL, et al. A new health promotion model for lone workers: results of the Safety \& Health Involvement For Truckers (SHIFT) pilot study. J Occup Environ Med 2009;51:1233-46.

27 Sharma PK, Ganguly E. Morbidity profile of long distance truck drivers in Hyderabad City, India. J Dr NTR Univ Health Sci 2014;3:234-7

28 Thiese MS, Effiong AC, Ott U, et al. A clinical trial on weight loss among truck drivers. Int J Occup Environ Med 2015;6:104-12.

29 van der Beek AJ, Meijman TF, Frings-Dresen MH, et al. Lorry drivers' work stress evaluated by catecholamines excreted in urine. Occup Environ Med 1995;52:464-9.

30 Whitfield Jacobson PJ, Prawitz AD, Lukaszuk JM, et al. Long-haul truck drivers want healthful meal options at truck-stop restaurants. J Am Diet Assoc 2007;107:2125-9.

31 Wilson JL, Wolf DM, Olszewski KA. Reducing commercial truck driver BMI through motivational interviewing and self-efficacy. Workplace Health Saf 2018;66:270-5.

32 Martins AJ, Martini LA, Moreno CRC. Prudent diet is associated with low sleepiness among short-haul truck drivers. Nutrition 2019;63-64:61-8.

33 Shattell M, Apostolopoulos Y, Sönmez S, et al. Occupational stressors and the mental health of truckers. Issues Ment Health Nurs 2010;31:561-8.

34 Kartikeyan S, Gurav RB, Joshi SD, et al. Health and sociodemographic profile of transport workers 2004. 
35 Rice SM, Aucote HM, Eleftheriadis D, et al. Prevalence and cooccurrence of internalizing and Externalizing depression symptoms in a community sample of Australian male truck drivers. Am J Mens Health 2018;12:74-7.

36 Layne DM, Rogers B, Randolph SA. Health and gender comparisons in the long-haul trucking industry: a pilot study. Aaohn J 2009;57:405-13.

37 Apostolopoulos Y, Lemke MK, Hege A, et al. Work and chronic disease: comparison of cardiometabolic risk markers between truck drivers and the general US population. J Occup Environ Med 2016;58:1098-105.

38 Wideman L, Oberlin DJ, Sönmez S, et al. Obesity indices are predictive of elevated $\mathrm{C}$-reactive protein in long-haul truck drivers. Am J Ind Med 2016;59:665-75.

39 Hege A, Lemke MK, Apostolopoulos Y, et al. Occupational health disparities among U.S. long-haul truck drivers: the influence of work organization and sleep on cardiovascular and metabolic disease risk. PLoS One 2018;13:e0207322.

40 Cavagioni LC, Geraldo Pierin AM, Pierin AMG. Hypertension and obesity among professional drivers who work transporting loads. ACTA Paul Enferm 2010;23:455-60.

41 Olson R, Thompson SV, Wipfli B, et al. Sleep, dietary, and exercise behavioral clusters among truck drivers with obesity: implications for interventions. J Occup Environ Med 2016;58:314-21.

42 Olson R, Wipfli B, Thompson SV, et al. Weight control intervention for truck drivers: the shift randomized controlled trial, United States. Am J Public Health 2016;106:1698-706.

43 Rosso GL, Montomoli C, Candura SM. Poor weight control, alcoholic beverage consumption and sudden sleep onset at the wheel among Italian truck drivers: a preliminary pilot study. Int $J$ Occup Med Environ Health 2016;29:405-16.

44 Apostolopoulos Y, Sönmez S, Shattell MM, et al. Health survey of U.S. long-haul truck drivers: work environment, physical health, and healthcare access. Work 2013;46:113-23.

45 Ulhôa MA, Marqueze EC, Lemos LC, et al. Minor psychiatric disorders and working conditions in truck drivers. Rev Saude Publica 2010;44:1130-6.

46 Stoohs RA, Guilleminault C, Dement WC. Sleep apnea and hypertension in commercial truck drivers. Sleep 1993;16:S11-13.

47 Varela-Mato V, O'Shea O, King JA, et al. Cross-sectional surveillance study to phenotype lorry drivers' sedentary behaviours, physical activity and cardio-metabolic health. BMJ Open 2017;7:e013162.

48 Angeles R, McDonough B, Howard M, et al. Primary health care needs for a priority population: a survey of professional truck drivers. Work 2014:49:175-81.

49 Bachmann LH, Lichtenstein B, St. Lawrence JS, et al. Health risks of American long-distance Truckers. J Occup Environ Med 2018;60:e349-55.

50 Brown DJ, Hagger MS, Morrissey S, et al. Predicting fruit and vegetable consumption in long-haul heavy goods vehicle drivers: application of a multi-theory, dual-phase model and the contribution of past behaviour. Appetite 2018;121:326-36.

51 Hamilton K, Vayro C, Schwarzer R. Social cognitive antecedents of fruit and vegetable consumption in truck drivers: a sequential mediation analysis. J Nutr Educ Behav 2015;47:379-84.

52 Ohlendorf D, Troebs P, Lenk A, et al. Postural sway, working years and BMI in healthy truck drivers: an observational study. BMJ Open 2017;7:e013281.

53 dos RLAP, Costa CDD, Rodrigues DS, et al. Obesity, hypertension and diabetes among truck drivers in the middle-west, Brazil. Biosci J 2017:33:485-93.

54 Suwazono Y, Okubo Y, Kobayashi E, et al. Effect of truck driving on health of Japanese middle aged male workers of a transport company - Multiple regression analyses for blood pressure and $\mathrm{HbA}$ 11 -. J Occup Health 2000;42:239-44.

55 Turner LM, Reed DB. Exercise among commercial truck drivers. Aaohn J 2011;59:429-36.

56 Wong CKH, Fung CSC, Siu S-C, et al. The impact of work nature, lifestyle, and obesity on health-related quality of life in Chinese professional drivers. J Occup Environ Med 2012;54:989-94.

57 Yen W-JJ, Ayodele O, McCarthy A. Predictors of intentions to make healthier eating choices among midwestern truck drivers. $J$ Epidemiol Glob Health 2019;9:309-14.

58 Yosef T, Belachew A, Tefera Y. Magnitude and contributing factors of low back pain among long distance truck drivers at modjo dry Port, Ethiopia: a cross-sectional study. J Environ Public Health 2019;2019:1-7.

59 Sendall MC, McCosker LK, Ahmed R, et al. Truckies' nutrition and physical activity: a cross-sectional survey in Queensland, Australia. Int J Occup Environ Med 2019;10:145-50.
60 Lemke MK, Apostolopoulos Y, Hege A, et al. Work organization, sleep and metabolic syndrome among long-haul truck drivers. Occup Med 2017;67:274-81.

61 Lemke MK, Apostolopoulos Y, Hege A, et al. Work, sleep, and cholesterol levels of U.S. long-haul truck drivers. Ind Health 2017;55:149-61.

62 Hege A, Lemke MK, Apostolopoulos Y, et al. The impact of work organization, job stress, and sleep on the health behaviors and outcomes of U.S. long-haul truck drivers. Health Educ Behav 2019;46:626-36.

63 Cavagioni LC, Geraldo Pierin AM. Health problems, hypertension and predisposition to stress in truck drivers. Rev DA Esc Enferm DA USP 2009;43:1263-7.

64 Reed DB, Cronin JS. Health on the road: issues faced by female truck drivers. Aaohn J 2003;51:120-5.

65 Wong WCW, Tam SM, Leung PWS. Cross-border truck drivers in Hong Kong: their psychological health, sexual dysfunctions and sexual risk behaviors. J Travel Med 2007:14:20-30.

66 Shen S, Li Y, Zhou M, et al. Depression status and associated factors in Chinese occupational truck drivers. Cell Biochem Biophys 2013;67:1497-500.

67 Orris $\mathrm{P}$, Hartman DE, Strauss $\mathrm{P}$, et al. Stress among package truck drivers. Am J Ind Med 1997;31:202-10.

68 Romo ML, George G, Mantell JE, et al. Depression and sexual risk behavior among long-distance truck drivers at roadside wellness clinics in Kenya. PeerJ 2019;7:e7253.

69 Thiese MS, Ott U, Robbins R, et al. Factors associated with truck crashes in a large cross section of commercial motor vehicle drivers. J Occup Environ Med 2015;57:1098-106.

70 Sharwood LN, Elkington J, Stevenson M, et al. Assessing sleepiness and sleep disorders in Australian long-distance commercial vehicle drivers: self-report versus an "at home" monitoring device. Sleep 2012;35:469-75.

71 Guglielmi O, Magnavita N, Garbarino S. Sleep quality, obstructive sleep apnea, and psychological distress in truck drivers: a crosssectional study. Soc Psychiatry Psychiatr Epidemiol 2018;53:531-6.

72 Riva MM, Cantamessa F, Borleri D, et al. Occupational health and safety of road haulage company employees. Med Lav 2018:109:180-9.

73 Lalla-Edward ST, Fischer AE, Venter WDF, et al. Cross-sectional study of the health of southern African truck drivers. BMJ Open 2019;9:e032025.

74 Girotto E, Bortoletto MSS, González AD, et al. Working conditions and sleepiness while driving among truck drivers. Traffic Inj Prev 2019;20:504-9.

75 Solomon AJ, Doucette JT, Garland E, et al. Healthcare and the long haul: Long distance truck drivers--a medically underserved population. Am J Ind Med 2004;46:463-71.

76 Fan ZJ, Bonauto DK, Foley MP, et al. Occupation and the prevalence of current depression and frequent mental distress, WA BRFSS 2006 and 2008. Am J Ind Med 2012;55:893-903.

77 Aguilar-Zinser V, Irigoyen ME, Rivera G, et al. Cigarette smoking and dental caries among professional truck drivers in Mexico. Caries Res 2008;42:255-62.

78 Thiese MS, Moffitt G, Hanowski RJ, et al. Repeated cross-sectional assessment of commercial truck driver health. J Occup Environ Med 2015;57:1022-7.

79 Thiese MS, Moffitt G, Hanowski RJ, et al. Commercial driver medical examinations: prevalence of obesity, comorbidities, and certification outcomes. J Occup Environ Med 2015;57:659-65.

80 Cui R, Tanigawa T, Sakurai S, et al. Relationships between sleepdisordered breathing and blood pressure and excessive daytime sleepiness among truck drivers. Hypertens Res 2006;29:605-10.

81 Filomeno R, Ikeda A, Maruyama K, et al. Excessive daytime sleepiness and alcohol consumption among commercial drivers. Occup Med 2019;69:406-11.

82 Cui R, Tanigawa T, Nakano H, et al. Associations between weight change since 20 years of age and sleep-disordered breathing among male truck drivers. Int J Obes 2009;33:1396-401.

83 Ebrahimi MH, Delvarianzadeh M, Saadat S. Prevalence of metabolic syndrome among Iranian occupational drivers. Diabetes Metab Syndr 2016;10:S46-51.

84 Guan J, Hsiao H, Bradtmiller B, et al. U.S. truck driver anthropometric study and multivariate anthropometric models for cab designs. Hum Factors 2012;54:849-71.

85 Kanazawa H, Suzuki M, Onoda T, et al. Excess workload and sleeprelated symptoms among commercial long-haul truck drivers. Sleep Biol Rhythms 2006;4:121-8.

86 Korelitz JJ, Fernandez AA, Uyeda VJ, et al. Health habits and risk factors among truck drivers visiting a health booth during a trucker trade show. Am J Health Promot 1993;8:117-23. 
87 Mansur AdeP, Rocha MA, Leyton V, et al. Risk factors for cardiovascular disease, metabolic syndrome and sleepiness in truck drivers. Arq Bras Cardiol 2015;105:560-5.

88 Moreno CRC, Louzada FM, Teixeira LR, et al. Short sleep is associated with obesity among truck drivers. Chronobiol Int 2006;23:1295-303.

89 Sieber WK, Robinson CF, Birdsey J, et al. Obesity and other risk factors: the National survey of U.S. long-haul truck driver health and injury. Am J Ind Med 2014;57:615-26.

90 Hilton MF, Staddon Z, Sheridan J, et al. The impact of mental health symptoms on heavy goods vehicle drivers' performance. Accid Anal Prev 2009;41:453-61.

91 Jain NB, Hart JE, Smith TJ, et al. Smoking behavior in trucking industry workers. Am J Ind Med 2006;49:1013-20.

92 Leyton V, Bombana HS, Magalhães JG, et al. Trends in the use of psychoactive substances by truck drivers in São Paulo state, Brazil: a time-series cross sectional roadside survey (2009-2016). Traffic Inj Prev 2019;20:122-7.

93 Stoynev AG, Minkova NK. Circadian rhythms of arterial pressure, heart rate and oral temperature in truck drivers. Occup Med 1997:47:151-4.

94 Hege A, Lemke MK, Apostolopoulos Y, et al. US long-haul truck driver work organization and the association with cardiometabolic disease risk. Arch Environ Occup Health 2017;72:303-10.

95 Hege A, Apostolopoulos Y, Perko M, et al. The work organization of long-haul truck drivers and the association with body mass index. $J$ Occup Environ Med 2016;58:712-7.

96 Rosso GL, Perotto M, Feola M, et al. Investigating obesity among professional drivers: the high risk professional driver study. Am J Ind Med 2015;58:212-9.

97 Sangaleti CT, Trincaus MR, Baratieri T, et al. Prevalence of cardiovascular risk factors among truck drivers in the South of Brazil. BMC Public Health 2014;14:1063.

98 Martin BC, Church TS, Bonnell R, et al. The impact of overweight and obesity on the direct medical costs of truck drivers. J Occup Environ Med 2009;51:180-4.

99 Franzini Codarin MA, Moulatlet EM, Nehme P, et al. Association between practice of physical activity, educational level and food intake profile of truck drivers. SAUDE E Soc 2010;19:418-28.

100 Wiegand DM, Hanowski RJ, McDonald SE. Commercial drivers health: a naturalistic study of body mass index, fatigue, and involvement in safety-critical events. Traffic Inj Prev 2009;10:573-9.

101 Robinson CF, Burnett CA. Truck drivers and heart disease in the United States, 1979-1990. Am J Ind Med 2005;47:113-9.

102 National Institutes for Health and Clinical Excellence. Public health draft guidance assessing body mass index and waist circumference thresholds for intervening to prevent ill health and premature death among adults from black, Asian and other minority ethnic groups in the UK 1 introduction, 2011. Available: https://www.nice.org.uk/ guidance/ph46/documents/bmi-and-waist-circumference-blackand-minority-ethnic-groups-draft-guidance2

103 Chankaramangalam MA, Ramamoorthy V, Muthuraja D, et al. Factors associated with hypertension among truck drivers: a cross sectional study at a check post on a national highway in South India. Int J Med Res Heal Sci 2017;6:126-9.

104 Public Health Draft Guidance. Assessing body mass index and waist circumference thresholds for intervening to prevent ill health and premature death among adults from black, Asian and other minority ethnic groups in the UK 1 introduction

105 Kearney PM, Whelton M, Reynolds K, et al. Global burden of hypertension: analysis of worldwide data. Lancet 2005;365:217-23.

106 Bachmann LH, Lichtenstein B, St Lawrence JS, et al. Health risks of American long-distance Truckers: results from a multisite assessment. J Occup Environ Med 2018;60:e349-55.

107 National Cholesterol Education Program (NCEP) Expert Panel on Detection, Evaluation, and Treatment of High Blood Cholestero in Adults (Adult Treatment Panel III). Third report of the National cholesterol education program (NCEP) expert panel on detection, evaluation, and treatment of high blood cholesterol in adults (adult treatment panel III) final report. Circulation 2002;106:3143-421.

108 ADA. American diabetes association, 2020. Available: https://www. diabetes.org/.[Accessed 26 May 2020].

109 International Diabetes Federation T The IDF consensus worldwide definition of metabolic syndrome, 2006. Available: file:///C:/Users/ psag2/Downloads/IDF_Meta_def_final.pdf [Accessed 4 Apr 2019].

110 Hatami A, Vosoughi S, Hosseini AF, et al. Effect of co-driver on job content and depression of truck drivers. Saf Health Work 2019;10:75-79.

111 Lewer D, O'Reilly C, Mojtabai R, et al. Antidepressant use in 27 European countries: associations with sociodemographic, cultural and economic factors. Br J Psychiatry 2015;207:221-6.

112 de Croon EM, Sluiter JK, Blonk RWB, et al. Stressful work, psychological job strain, and turnover: a 2-year prospective cohort study of truck drivers. J Appl Psychol 2004;89:442-54.

113 Aune D, Giovannucci E, Boffetta P, et al. Fruit and vegetable intake and the risk of cardiovascular disease, total cancer and all-cause mortality-a systematic review and dose-response meta-analysis of prospective studies. Int J Epidemiol 2017;46:1029-56.

114 Uauy R, Kumanyika S, Seidell J, et al. WHO independent expert report on diet and chronic disease, 2003. Available: https://www. who.int/mediacentre/news/releases/2003/pr20/en/ [Accessed 26 May 2020].

115 Cohen DA, Story M. Mitigating the health risks of dining out: the need for standardized portion sizes in restaurants. Am J Public Health 2014:104:586-90.

116 World Health Organisation. Global recommendations on physical activity for health, 2011. Available: https://www.who.int/ dietphysicalactivity/physical-activity-recommendations-18-64years. pdf

117 WHO. Who global report on trends in prevalence of tobacco smoking, 2015. Available: www.who.int [Accessed 31 Mar 2020].

118 Costello B, Karickhoff A. Truck driver shortage analysis, 2019. Available: www.atabusinesssolutions.com [Accessed 4 Nov 2019].

119 Husting L, Biddle EA. Truck Safety in the Age of Information. In: Trucking in the age of information. Routledge, 2005.

120 Quintiliani L, Yang M, Sorensen G. A process evaluation of tobaccorelated outcomes from a telephone and print-delivered intervention for motor freight workers. Addict Behav 2010:35:1036-9.

121 Bashkireva AS, Artamonova VG, Khavinson VK. [Productive aging or "healthy worker effect"? Retrospective analysis of morbidity in motor transport drivers]. Adv Gerontol 2009;22:539-47.

122 International Federation Diabetes. Worldwide Toll of Diabetes. In: IDF diabetes atlas. 9 edn. Brussels, Belgium, 2019. https:// diabetesatlas.org/en/sections/worldwide-toll-of-diabetes.html

123 Gjerde H, Christophersen AS, Normann PT, et al. Analysis of alcohol and drugs in oral fluid from truck drivers in Norway. Traffic Inj Prev 2012;13:43-8.

124 Gill PE, Wijk K. Case study of a healthy eating intervention for Swedish lorry drivers. Health Educ Res 2004:19:306-15.

125 Abu Dabrh AM, Firwana B, Cowl CT, et al. Health assessment of commercial drivers: a meta-narrative systematic review. BMJ Open 2014:4:e003434.

126 Crizzle AM, Bigelow P, Adams D, et al. Health and wellness of long-haul truck and bus drivers: a systematic literature review and directions for future research. J Transp Health 2017;7:90-109.

127 Prince SA, Elliott CG, Scott K, et al. Device-measured physical activity, sedentary behaviour and cardiometabolic health and fitness across occupational groups: a systematic review and metaanalysis. Int J Behav Nutr Phys Act 2019;16:30.

128 Erin Mabry J, Hosig K, Hanowski R, et al. Prevalence of metabolic syndrome in commercial truck drivers: a review. $J$ Transp Health 2016;3:413-21. 